\title{
NUMERICAL STUDIES WITH A REGIONAL ATMOSPHERIC CLIMATE MODEL BASED ON CHANGES IN THE ROUGHNESS LENGTH FOR MOMENTUM AND HEAT OVER ANTARCTICA
}

\author{
C. H. REIJMER ${ }^{1}$, E. VAN MEIJGAARD ${ }^{2}$ and M. R. VAN DEN BROEKE ${ }^{1}$ \\ ${ }^{1}$ Institute for Marine and Atmospheric Research, Utrecht University, Utrecht, The Netherlands; \\ ${ }^{2}$ Royal Netherlands Meteorological Institute, de Bilt, The Netherlands
}

(Received in final form 25 April 2003)

\begin{abstract}
A regional atmospheric climate model is used to examine the effect of changes in the roughness lengths of momentum $\left(z_{0 m}\right)$ and heat $\left(z_{0 h}\right)$ on the structure of the lower atmosphere and on the surface energy fluxes over Antarctica. Four experiments were carried out in which $z_{0 m}$ and/or $z_{0 h}$ were altered with respect to a control experiment. The changes consisted of (1) a lowering of $z_{0 m}$ from a field aggregated from a vegetation map with an orographic correction based on the European Centre for Medium-Range Weather Forecasts $z_{0 m}$ field, to a constant value of $10^{-3} \mathrm{~m}$; and (2) a lowering of $z_{0 h}$ from a value equal to $z_{0 m}$ to a constant value of $10^{-3} \mathrm{~m}$ or a value dependent on the wind speed via a surface renewal model. A reduction of $z_{0 m}$ results in the expected increase in near-surface wind speed. It also results in an increase in the depth of the layer in which southeasterly near-surface winds prevail, and in a decrease in the strength of the large-scale flow over the continent, in particular in summer. In the escarpment region a decrease of $z_{0 m}$ is found to result in too high wind speeds. Surface temperatures on average decrease while atmospheric temperatures increase, resulting in an increase of near-surface static stability. Changes in roughness lengths do not significantly change the temperature profiles. The surface fluxes, on average found reduced, are modelled best by using the $z_{0 h}$ based on the surface renewal method.
\end{abstract}

Keywords: Antarctica, Momentum roughness, Numerical experiment, Regional atmospheric climate model, Scalar roughness length, Turbulent fluxes.

\section{Introduction}

In recent years several ice cores have been drilled in the Antarctic and Greenland ice sheets; in order to improve the interpretation of the climate records obtained from such ice cores a number of studies have been carried out to examine the processes involved in the interaction between the snow surface and the atmosphere. These studies use data from (automatic) weather stations and atmospheric models for weather and climate prediction (henceforth atmospheric models) to examine the surface mass balance, the surface energy budget and the near-surface meteorological conditions over ice and snow surfaces (Krinner et al., 1997; Turner et al., 1999; Reijmer and Oerlemans, 2002; Van den Broeke et al., 2002; Van Lipzig et al., 2002).

The atmospheric models are a very suitable tool to obtain a continent wide picture of the processes involved in the air-snow interaction. A crucial part in this 
interaction is played by the surface turbulent fluxes of momentum, heat and moisture; these fluxes are closely related to the atmospheric vertical gradients of wind speed, temperature and humidity. In the models these fluxes are usually calculated using transfer coefficients and Monin-Obukhov similarity theory (Garratt, 1992; Beljaars and Viterbo, 1998). The transfer coefficients are approximate analytical expressions written in terms of profile functions, which contain the surface characteristics in terms of roughness lengths, and functions describing the stability of the surface layer. In recent years much effort has been put into the improvement of the stability functions for stable conditions as found over ice and snow surfaces (Handorf et al., 1999; Cassano et al., 2001; King et al., 2001; Zilitinkevich et al., 2002). The transfer coefficients, and hence the turbulent fluxes, are also sensitive to the choice of the surface roughness lengths for momentum $\left(z_{0 m}\right)$, heat $\left(z_{0 h}\right)$ and moisture $\left(z_{0 q}\right)$. They are defined as the height at which the extrapolated profiles of, respectively, wind speed, temperature and specific humidity reach their surface values. In atmospheric models the roughness lengths for land surfaces are prescribed surface characteristic fields in which the effects of vegetation, urbanization and orography are combined. The methods used to generate these fields are based on empirical results.

A reasonable estimate of the surface roughness lengths can be obtained from observations, using the downward extrapolation of log-linear profiles of wind speed, potential temperature and specific humidity to their surface values. The surface value for wind speed is $0 \mathrm{~m} \mathrm{~s}^{-1}$; the surface value for temperature can be determined from measurements of the longwave outgoing radiation, and the surface value for humidity can be determined using the surface value for temperature and assuming that the air near the snow surface is saturated. However, longwave radiation is often not measured and the surface values of temperature and humidity are, therefore, not well known, which complicates the determination of $z_{0 h}$ and $z_{0 q}$. Other complications in the aggregation of surface roughness length fields for atmospheric models are the limited amount of measurements of the roughness lengths over the Antarctic continent (Inoue, 1989; King and Anderson, 1994; Bintanja and van den Broeke, 1995; Bintanja, 2000) and the fact that the measurements produce local values of the roughness lengths while grid-averaged values are necessary. An additional problem is that the roughness lengths are determined mainly by the shape and distribution of surface roughness elements. When these elements are flexible or moving, $z_{0 m}, z_{0 h}$ and $z_{0 q}$ may depend on the wind speed, for example in the case of snow drift (Bintanja and Reijmer, 2001).

Several studies presenting model estimates or measurements of the roughnesss lengths are available (King, 1990; King and Anderson, 1994; Bintanja and van den Broeke, 1995; Andreas, 2002). However, measurements are still limited and the scatter in the results considerable, especially for $z_{0 h}$ and $z_{0 q}$. Owing to the lack of measurements, $z_{0 h}$ and $z_{0 q}$ in atmospheric models are often set equal to $z_{0 m}$ or $z_{0 m} / 10$, noting that $z_{0 h}$ and $z_{0 q}$ will differ from $z_{0 m}$ because the transfer mechanisms are different. The most efficient transfer of momentum to the surface is through 
pressure fluctuation gradients across roughness elements. On the other hand, the transport of heat and moisture depends on molecular diffusion. These differences in transfer mechanisms and the use of $z_{0 h}=z_{0 q}=z_{0 m}$ or $z_{0 m} / 10$ may result in too much evaporation and sublimation, especially in mountainous areas (Beljaars and Viterbo, 1994; Van Lipzig et al., 2002). Over Antarctica this also results in a bias in the sensible heat flux (Cassano et al., 2001). This emphasizes the necessity of using different parameterisations for $z_{0 h}$ and $z_{0 q}$ in atmospheric models.

In this paper we examine the effect of changes in $z_{0 m}$ and $z_{0 h}$ on the general structure of the lower atmosphere, and on the surface energy fluxes over Antarctica, by means of a regional atmospheric climate model. In Section 2 the experimental set-up is described. The results are presented in Section 3, followed by a summary and concluding remarks.

\section{Experimental Set-Up}

We use the Regional Atmospheric Climate Model (RACMO) for this study (Christensen et al., 1996), which is extensively described and evaluated for Antarctica by Van Lipzig et al. (1999). Here, we give a short summary of the important features of the model.

The model covers the Antarctic continent and part of the Southern Ocean. The horizontal resolution is $55 \mathrm{~km}$ and there are 20 hybrid-levels in the vertical of which the lowest is at $7 \mathrm{~m}$ above the surface. The parameterisations of the physical processes are taken from the ECHAM4 model (Roeckner et al., 1996) with some adjustments to improve the representation of physical processes over Antarctica (Van Lipzig et al., 1999). The formulation of the dynamical processes is adopted from the High-Resolution Limited Area Model (HIRLAM) (Gustafsson, 1993). The model is initialised once and forced every six hours at the lateral boundaries and at the sea surface by European Center for Medium-Range Weather Forecasts (ECMWF) operational analyses. The inner part of the model is allowed to evolve freely.

In the surface scheme of RACMO the surface turbulent fluxes are calculated from Monin-Obukhov similarity theory using approximate analytical expressions for the transfer coefficients based on Louis (1979) (see Roeckner et al., 1996). The surface roughness lengths are defined according to common practice in present-day atmospheric models (Beljars and Viterbo, 1998). The model distinguishes between three surface types; sea, sea ice and land surfaces; ice shelves are treated as grounded ice, and are therefore considered part of the Antarctic continent and treated as a land surface. Over sea, $z_{0 m}$ is described as a function of wind speed in terms of the friction velocity $\left(u_{*}\right)$ (Charnock, 1955). $z_{0 q}$ equals $z_{0 h}$ and is calculated as a function of $z_{0 m}$ using a relation based on empirical results. Over sea ice, $z_{0 m}$ is taken as $10^{-3} \mathrm{~m}$, with $z_{0 q}$ equal to $z_{0 h}$ and assumed to be $10^{-5} \mathrm{~m}$. Both values are based on characteristic values of $z_{0 m}$ and $z_{0 h}$ for snow and ice surfaces. For land surfaces 


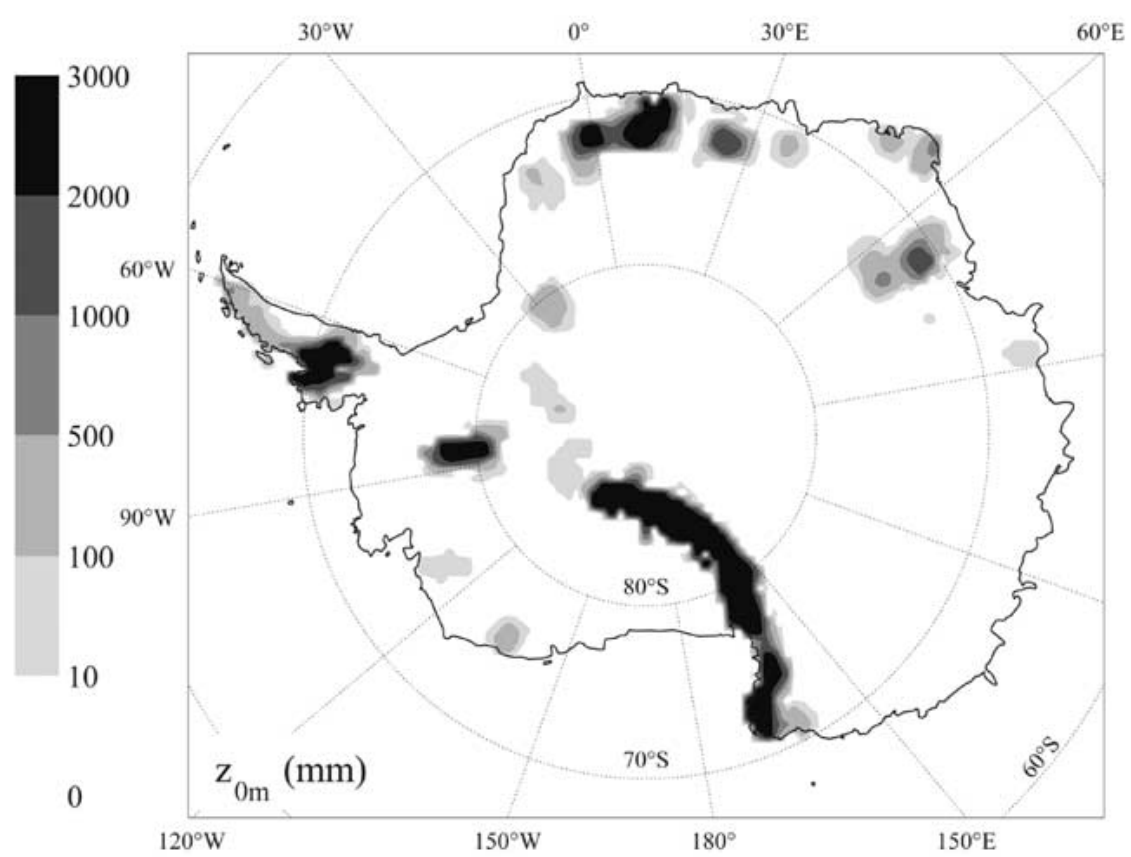

Figure 1. Surface roughness length for momentum $\left(z_{0 m}\right)$ for Antarctica as used in experiments CTL, CNS and AND based on the ECMWF field maximized at $3 \mathrm{~m}$.

in general the $z_{0 m}$ field is aggregated from a vegetation map with corrections due to urbanization and variations in orography (Figure 1). For the Antarctic continent urbanization is absent and the vegetation type is bare soil covered with snow. The orographic component describes the influence of subgrid variations in orography on the grid-scale flow. The correction makes use of a characteristic length scale of the subgrid-scale orography and a slope parameter describing the wind swept area of obstacles. $z_{0 h}$ is taken equal to $z_{0 m}$ and, as for sea and sea ice, $z_{0 q}$ is assumed equal to $z_{0 h}$. Furthermore, $z_{0 m}$ is limited to a maximum of $3 \mathrm{~m}$ to constrain it to values smaller than the altitude of the lowest model level.

Four numerical experiments (henceforth experiments) were carried out in which $z_{0 m}$ and/or $z_{0 h}$ were altered with respect to a control experiment (CTL) (Table I). In CTL the $z_{0 m}$ field of the ECMWF model (Figure 1) is adopted (henceforth CTL field). In all experiments the assumption is made that $z_{0 q}$ equals $z_{0 h}$. Furthermore, only the formulation of $z_{0 m}$ and $z_{0 h}$ over the Antarctic continent and ice shelves is changed, not over sea or sea ice. In all experiments $z_{0 m}$ and $z_{0 h}$ are limited to a maximum of $3 \mathrm{~m}$. Each experiment consists of a summer and a winter month, January and July 1998.

In experiments CNS and AND $z_{0 m}$ is equal to that in CTL whereas in experiments CNSC and ANDC $z_{0 m}$ has a constant value of $10^{-3} \mathrm{~m}$, a value usually taken for snow and ice surfaces without any correction for urbanization or orography. 


\section{TABLE I}

Summary of the numerical experi-
ments. ECMWF is the ECMWF $z_{0 m}$
field limited to $3 \mathrm{~m}$ (Figure 1), An-
dreas is the surface renewal model of
Andreas (1987) with $z_{0 m}=10^{-3} \mathrm{~m}$.
\begin{tabular}{lll} 
Experiment & $z_{0 m}$ & $z_{0 h}$ \\
\hline CTL & ECMWF & $z_{0 m}$ \\
CNS & ECMWF & $10^{-3} \mathrm{~m}$ \\
CNSC & $10^{-3} \mathrm{~m}$ & $10^{-3} \mathrm{~m}$ \\
AND & ECMWF Andreas \\
ANDC & $10^{-3} \mathrm{~m}$ & Andreas
\end{tabular}

For $z_{0 h}$ three formulations are tested (Table I). In CTL $z_{0 h}$ equals $z_{0 m}$, in CNS and CNSC $z_{0 h}$ is a constant value of $10^{-3} \mathrm{~m}$, and in AND and ANDC $z_{0 h}$ is a function of the atmospheric conditions by using the surface renewal model of Andreas (1987). The surface renewal model predicts $\ln \left(z_{0 h} / z_{0 m}\right)$ as a function of the roughness Reynolds number $\left(\mathrm{Re}_{*}\right)$ :

$$
\begin{aligned}
& \operatorname{Re}_{*}=\frac{u_{*} z_{0 m}}{v}, \\
& \ln \left(\frac{z_{0 h}}{z_{0 m}}\right)=a_{1}+a_{2} \ln \left(\operatorname{Re}_{*}\right)+a_{3} \ln \left(\operatorname{Re}_{*}\right)^{2} .
\end{aligned}
$$

Here, $u_{*}$ is the friction velocity and $v$ is the kinematic viscosity. The temperature dependency of $v$ is not taken into account, so a constant value of $1.35 \times 10^{-5} \mathrm{~m}^{2} \mathrm{~s}^{-1}$ is assumed. Andreas (1987) defines three regimes, a smooth regime $\left(\operatorname{Re}_{*} \leq 0.135\right)$, a transitional regime $\left(0.135<\operatorname{Re}_{*}<2.5\right)$ and a rough regime $\left(2.5 \leq \mathrm{Re}_{*} \leq\right.$ 1000), and the coefficients $a_{1}, a_{2}$ and $a_{3}$ differ per regime (Table II). Figure 2 illustrates the dependency of $\ln \left(z_{0 h} / z_{0 m}\right)$ on $\operatorname{Re}_{*}$. In the description of Andreas (1987) $z_{0 q}$ is not equal to $z_{0 h}$. Here, we assume that they are equal, which may result in a slight underestimation of the moisture fluxes but differences are small. In experiment AND, $z_{0 m}$ in Equation (2) is not taken equal to $z_{0 m}$ used in the model integration but is set to a constant value of $10^{-3} \mathrm{~m}$, neglecting the orographic influence incorporated in $z_{0 m}$ on $z_{0 h}$. This is justified by the fact that it is very plausible that the characteristic length scale of the diffusion process responsible for the transfer of heat and moisture is determined by the size of small-scale surface elements, and does not depend on larger scale inhomogeneities such as mountains (Smeets, 2000). Note that, since the ECMWF $z_{0 m}$ field is $\geq 10^{-3} \mathrm{~m}$ over the Antarctic continent, in all experiments the proposed changes in $z_{0 h}$ and $z_{0 m}$ make them smaller (or remain equal) compared to those in CTL. 


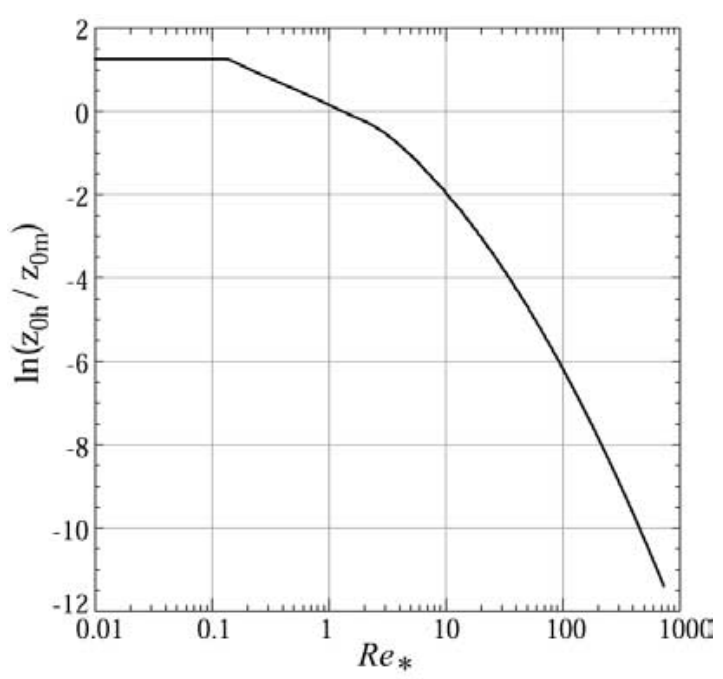

Figure 2. The $\ln \left(z_{0 h} / z_{0 m}\right)$ as a function of the roughness Reynolds number $\operatorname{Re}_{*}$ (Equation (2), Table II).

TABLE II

Coefficients used in Equation (2) (Andreas, 1987).

\begin{tabular}{llcc}
\hline & $\mathrm{Re}_{*} \leq 0.135$ & $0.135<\mathrm{Re}_{*}<2.5$ & $2.5 \leq \mathrm{Re}_{*} \leq 1000$ \\
\hline$a_{1}$ & 1.250 & 0.149 & 0.317 \\
$a_{2}-$ & -0.550 & -0.565 \\
$a_{3}-$ & - & -0.183 \\
\hline
\end{tabular}

The results of the experiments are presented in terms of changes with respect to CTL and compared with observations. The observations are (automatic) weather station data from 17 stations from the United States Antarctic Research Program (USARP) (Stearns et al., 1997), Neumayer station (König-Langlo et al., 1998), Halley station and six stations in Dronning Maud Land (DML) (Reijmer and Oerlemans, 2002) (Figure 3). Of these 25 stations, nine, among which Neumayer, are located on ice shelves, four are located in the escarpment region, and 12, among which South Pole, are located on the Antarctic Plateau. Furthermore, balloon soundings at Neumayer and South Pole for January and July 1998 are used. (Weather station data and balloon soundings for the USARP stations, Neumayer and Halley are available from http://uwamrc.ssec.wisc.edu/amrc/archiv.html, http://www.awi-bremerhaven.de/MET/Neumayer/met.html and http://www. antarctica.ac.uk/met/data.html, respectively.)

Due to the limited horizontal resolution of the model, steep slopes are flattened out, possibly resulting in inadequate values of elevation and slope at the model 


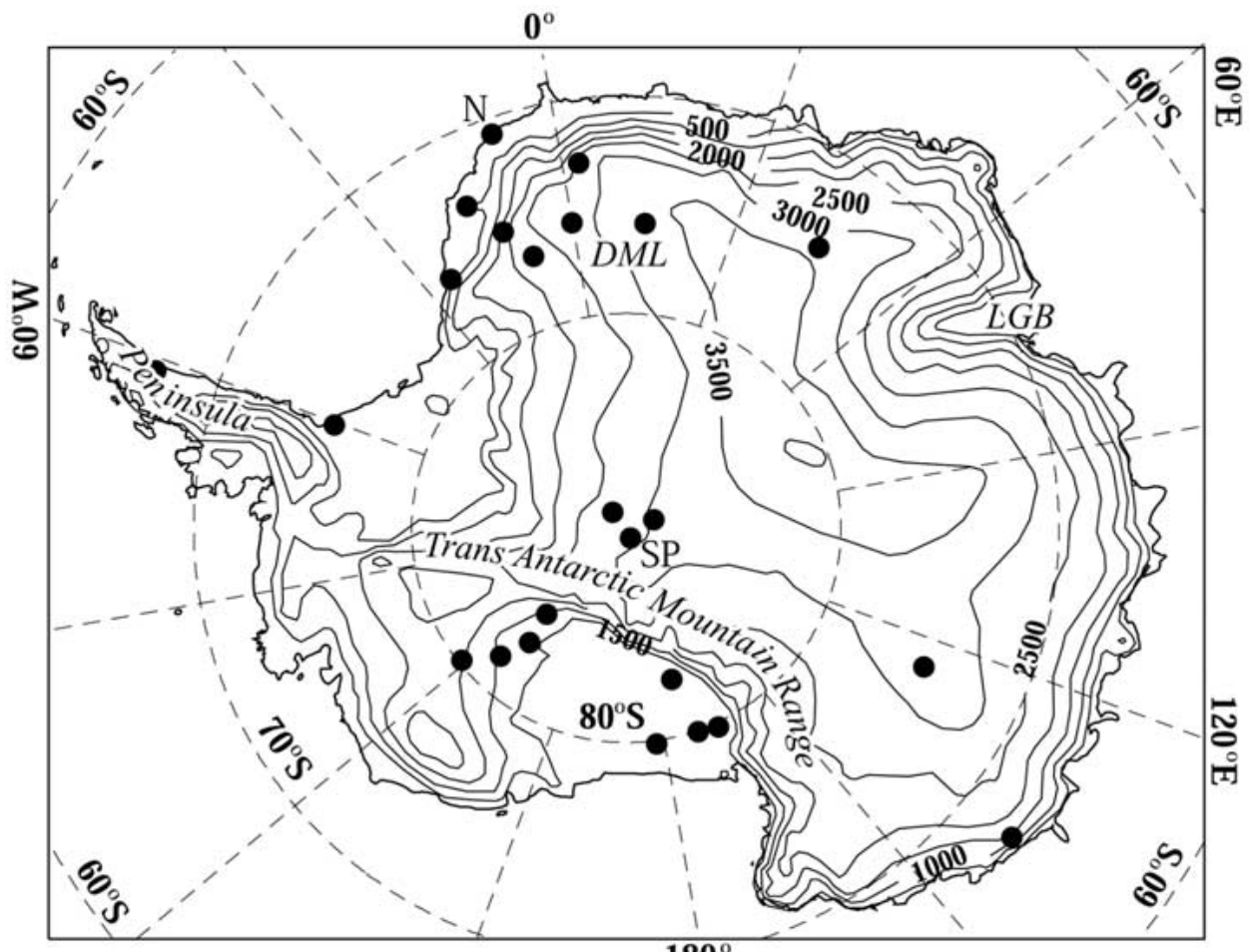

$180^{\circ}$

Figure 3. Topographic map of Antarctica. Elevation interval is $500 \mathrm{~m}$. Marked dots denote the locations of the (automatic) weather stations. N is Neumayer station, SP is South Pole station, DML is Dronning Maud Land and LGB is the Lambert Glacier basin.

grid point closest to the station location. Therefore, the closest grid point with a reasonable correspondence in elevation is chosen for the comparison with station data instead of the grid point closest to the measurement site. The chosen grid points are within $80 \mathrm{~km}$ of the measurement sites and the model elevation at these points is within $30 \mathrm{~m}$ of the actual elevation. The model slope is generally underestimated, the larger the slope the larger the underestimation of the slope in the model. The underestimation of the surface slope at the chosen model grid points is slightly larger than the surface slope of the model grid points that best represents the surface slope at the station locations. Temperatures and wind speeds are not corrected for the deviations in elevation and slope. 


\section{Results}

\subsection{SPATIAL VARIATIONS IN THE ROUGHNESS LENGTHS}

Figure 1 presents the $z_{0 m}$ field as used in experiments CTL, CNS and AND. The climatological value of $z_{0 m}$ for snow without the effect of orography taken into account is $10^{-3} \mathrm{~m}$, which is somewhat higher than the estimations of $z_{0 \mathrm{~m}}$ over Antarctica from measurements. Estimations from measurements for Antarctic snow surfaces range from $4.0 \times 10^{-6} \mathrm{~m}$ to $1.0 \times 10^{-3} \mathrm{~m}$ (Inoue, 1989; King and Turner, 1997; Bintanja, 2000). In the model values as large as $3 \mathrm{~m}$ (in the original ECMWF field $z_{0 m}$ is maximized at $100 \mathrm{~m}$ ) are found over the Transantarctic mountain range, the Antarctic Peninsula and in DML, areas where the orography is expected to have a large impact on the resolved flow. Over the rest of the continent $z_{0 m}$ is $10^{-3} \mathrm{~m}$.

The $z_{0 h}$ values in CNS, CNSC, AND and ANDC are considerably smaller than in CTL, but slightly larger than in the ECMWF model. In the ECMWF model $z_{0 h}$ is $z_{0 m} / 10$ or smaller owing to orography and varies between $10^{-4} \mathrm{~m}$ and $10^{-3} \mathrm{~m}$, with the smallest values in mountainous areas. In experiments CNS and CNSC $z_{0 h}$ is $10^{-3} \mathrm{~m}$. In experiments AND and ANDC $z_{0 h}$ depends on the near-surface wind speed via $u_{*}$, and varies between $10^{-2}$ and $0.5 \times 10^{-3} \mathrm{~m}$ (Figure 4). The dependence on wind speed results in a decrease in $z_{0 h}$ with increasing wind speed. Figure 4 presents the monthly averaged $z_{0 h}$ for ANDC for January and July 1998. The figure shows lower values of $z_{0 h}$ in the escarpment region of the East Antarctic plateau where wind speeds are higher. This is especially clear in July when the near-surface katabatic wind speeds are on average higher. The importance of the topography in forcing the katabatic wind is also visible, especially in July when the outlines of the topography of the East Antarctic plateau are clearly visible in the pattern of $z_{0 h}$ (Figure $4 \mathrm{~b}$ ). In AND (not shown) $z_{0 h}$ exhibits a similar pattern as in ANDC but with slightly lower values due to lower values of $u_{*}$. Since $z_{0 m}$ is smaller in ANDC compared to AND, the lower values of $z_{0 h}$ and $u_{*}$ in ANDC are due to the fact that the impact of a reduced $z_{0 m}$ on $u_{*}$ is larger than the effect of an increase in wind speed (caused by a reduction in $z_{0 m}$.

\subsection{IMPACT ON THE NEAR-SURFACE CONDITIONS}

\subsubsection{Wind Speed}

Changes in $z_{0 m}$ and $z_{0 h}$ have a large impact on the exchange of momentum, heat and moisture between surface and atmosphere and, consequently, on the structure of the overlying lower atmosphere. The basic effect of lowering $z_{0 m}$ is a reduction of the friction exerted by the surface on the atmospheric flow, resulting in an increase in the near-surface wind speed (Figure 5). The largest increase occurs in the escarpment regions where the decrease in $z_{0 m}$ is largest. In these areas the change in the monthly mean fields is significant at the 5\% level. The effect on wind speed of changing $z_{0 h}$ is an order of magnitude smaller than the effect of changing $z_{0 m}$ owing to the stability of the boundary layer. Monthly averaged regional changes of 

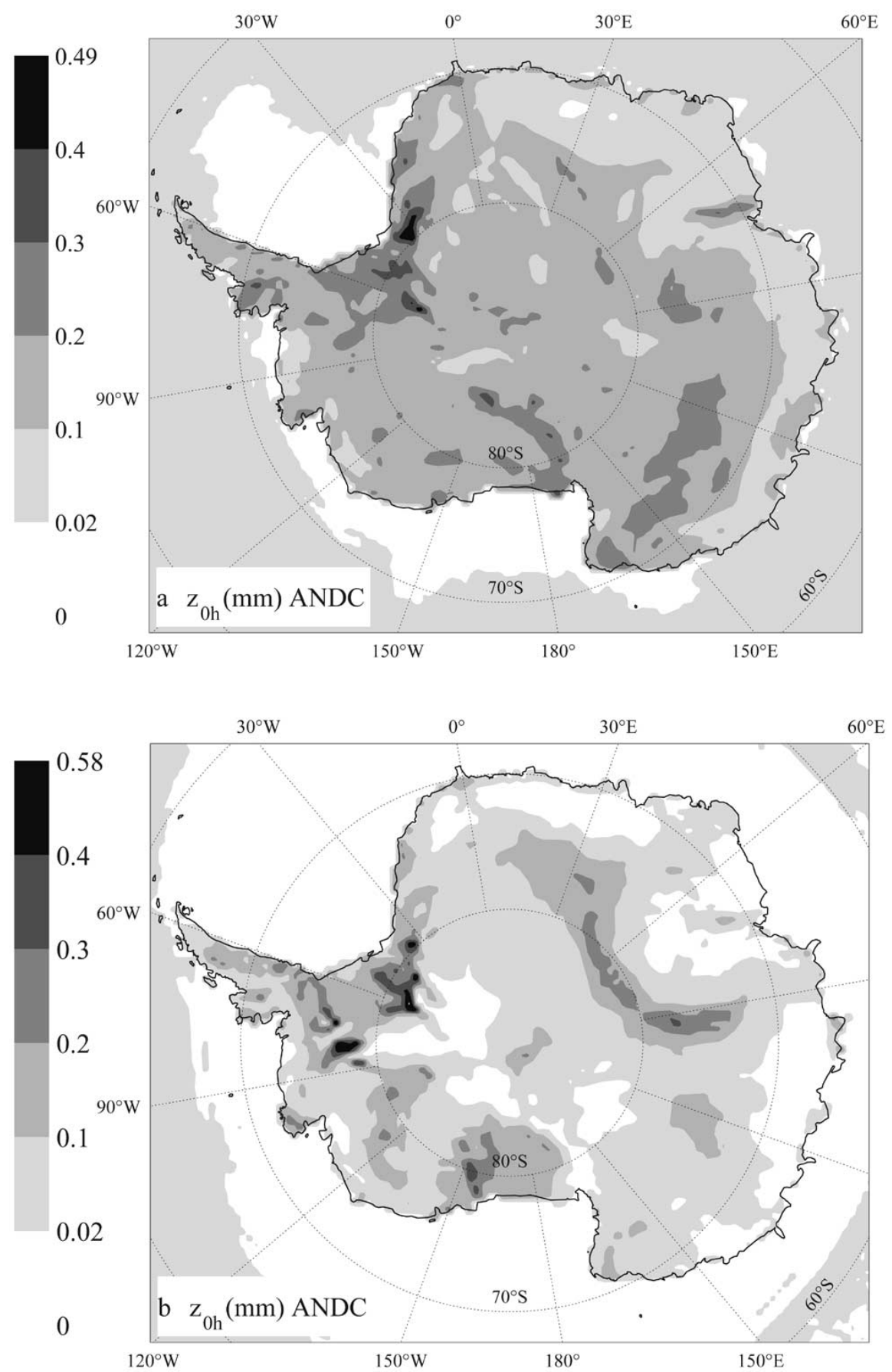

Figure 4. Monthly averaged surface roughness length for heat $\left(z_{0 h}\right)$ for January (a) and July (b) 1998 for ANDC. 
TABLE III

Monthly and continentally averaged 10-m wind speed $(W S)$, surface temperature $\left(T_{0}\right)$, temperature at the lowest model level $\left(T_{l v l}\right)$, surface sensible $(H)$ and latent $(L E)$ heat flux for January and July 1998.

\begin{tabular}{llllll}
\hline January & $W S\left(\mathrm{~m} \mathrm{~s}^{-1}\right)$ & $T_{0}(\mathrm{~K})$ & $T_{l v l}(\mathrm{~K})$ & $H\left(\mathrm{~W} \mathrm{~m}^{-2}\right)$ & $L E\left(\mathrm{~W} \mathrm{~m}^{-2}\right)$ \\
\hline CTL & 4.92 & 256.55 & 257.17 & 6.41 & -6.41 \\
CNS & 4.79 & 256.33 & 257.09 & 5.21 & -5.57 \\
CNSC & 5.32 & 256.49 & 257.23 & 5.46 & -5.35 \\
AND & 4.84 & 256.47 & 257.42 & 4.65 & -4.77 \\
ANDC & 5.25 & 256.51 & 257.40 & 4.65 & -4.58 \\
July & & & & & \\
\hline CTL & 8.19 & 226.75 & 229.40 & 38.08 & -1.25 \\
CNS & 8.20 & 226.31 & 229.24 & 36.89 & -0.97 \\
CNSC & 9.02 & 226.30 & 229.25 & 36.93 & -0.72 \\
AND & 8.22 & 225.86 & 229.86 & 34.87 & -0.59 \\
ANDC & 9.02 & 225.82 & 229.67 & 34.66 & -0.43 \\
\hline
\end{tabular}

$\pm 2 \mathrm{~m} \mathrm{~s}^{-1}$ occur due to changes in $z_{0 h}$ while a lowering of $z_{0 m}$ may result in regional wind speed increases of up to $10 \mathrm{~m} \mathrm{~s}^{-1}$. Averaged over the continent the $10-\mathrm{m}$ wind speed increases from 4.8 to $5.3 \mathrm{~m} \mathrm{~s}^{-1}$ in January and from 8.2 to $9.0 \mathrm{~m} \mathrm{~s}^{-1}$ in July when lowering $z_{0 m}$ from the CTL field to a constant value (Table III). On a continental scale, lowering $z_{0 h}$ has only a marginal effect on wind speed, especially in July.

The modelled $10-\mathrm{m}$ wind speeds are presented as monthly averages and compared with measurements in Figure 6 and Table IV. The figure presents the monthly mean difference between modelled and measured $10-\mathrm{m}$ wind speed as a function of the measurements for CTL and AND. The table presents the average biases and the standard deviations $(\sigma)$ of the differences. The average bias in the wind speed for this set of locations is slightly positive, the model overestimates the wind speed on average by $0.25 \mathrm{~m} \mathrm{~s}^{-1}$. A decrease in $z_{0 m}$ (CNSC and ANDC) increases the bias while a decrease in $z_{0 h}$ decreases the bias. The standard deviation decreases for all experiments compared to CTL with the lowest $\sigma$ for CNS and AND. Differences between the experiments are small owing to the fact that only for two sites is $z_{0 m}$ significantly larger than $10^{-3} \mathrm{~m}$ in the CTL field. The average reduction of $z_{0 \mathrm{~m}}$ and the impact on the average wind speed is therefore small. The figure shows that for stations with low wind speeds the model overestimates wind speed, while for high wind speed sites the wind speed is underestimated. The experiments with the CTL field for $z_{0 m}$ and a reduction of $z_{0 h}$ (CNS and AND) give the best agreement between measured and modelled near-surface wind speed. 

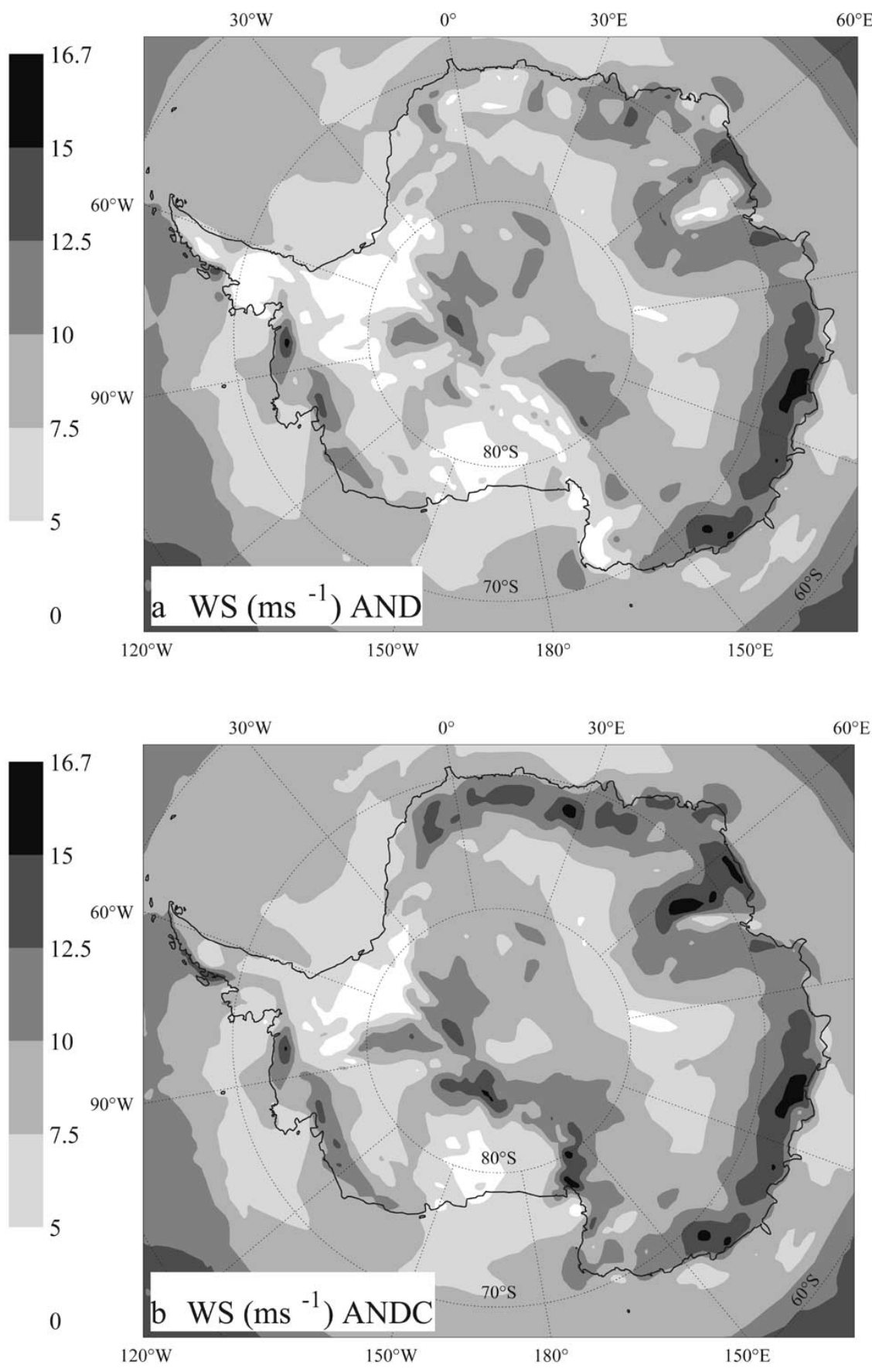

Figure 5. Monthly averaged 10-m wind speed for AND (a) and ANDC (b) for July 1998. 

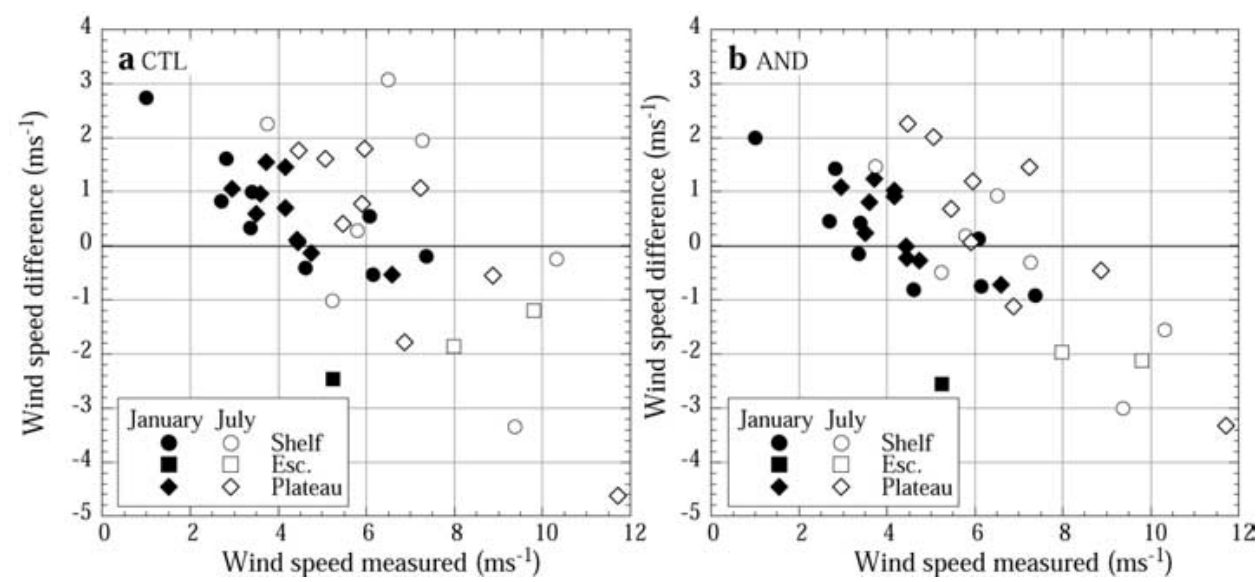

Figure 6. Monthly averaged 10-m wind speed difference (model-measurements) as a function of the measurements for CTL (a) and AND (b). Closed symbols represent January values, open symbols July values, Esc. is the escarpment. When the measurement height was not $10 \mathrm{~m}$ the measurements were recalculated to the model height by using a log-linear vertical wind speed profile.

\section{TABLE IV}

Statistics of the comparison between modelled and measured 10-m wind speed (WS), 2-m temperature $(T)$, surface sensible $(H)$ and latent $(L E)$ heat flux. Bias is the average difference (model-measurements), $\sigma$ is the standard deviation of the difference. $H$ and $L E$ are determined from measurements of wind speed, temperature and humidity using Monin-Obukhov similarity theory. Note that for $H$ and $L E$ only data from the DML AWS are available (Reijmer and Oerlemans, 2002).

\begin{tabular}{|c|c|c|c|c|c|c|c|c|}
\hline \multirow[b]{2}{*}{ Experiment } & \multicolumn{2}{|c|}{$W S\left(\mathrm{~m} \mathrm{~s}^{-1}\right)$} & \multicolumn{2}{|c|}{$T(\mathrm{~K})$} & \multicolumn{2}{|c|}{$H\left(\mathrm{~W} \mathrm{~m}^{-2}\right)$} & \multicolumn{2}{|c|}{$L E\left(\mathrm{~W} \mathrm{~m}^{-2}\right)$} \\
\hline & Bias & $\sigma$ & Bias & $\sigma$ & Bias & $\sigma$ & Bias & $\sigma$ \\
\hline CTL & 0.25 & 1.62 & 0.84 & 3.53 & 21.41 & 27.01 & -4.93 & 6.91 \\
\hline CNS & 0.01 & 1.39 & 0.28 & 3.23 & 17.05 & 21.63 & -3.03 & 4.38 \\
\hline CNSC & 0.39 & 1.52 & 0.62 & 3.33 & 17.34 & 21.14 & -2.33 & 3.94 \\
\hline AND & -0.02 & 1.38 & 0.28 & 3.33 & 13.87 & 18.02 & -1.87 & 2.94 \\
\hline ANDC & 0.37 & 1.45 & 0.68 & 3.37 & 14.43 & 18.18 & -1.36 & 2.38 \\
\hline
\end{tabular}

The two sites where $z_{0 m}$ is significantly larger than $10^{-3} \mathrm{~m}$ in the CTL field, viz. $1.095 \mathrm{~m}$ and $0.034 \mathrm{~m}$, respectively, are located in the escarpment region of DML. The increase in wind speed when reducing $z_{0 m}$ to a constant value of $10^{-3} \mathrm{~m}$ (CNSC and ANDC) is largest for these stations and results in wind speeds that are too high, while the wind speed for these stations are too low in CTL, CNS and AND (not shown). Over Antarctica, the near-surface wind speed and direction is largely determined by a semi-permanent katabatic flow. Since the katabatic winds are forced by cooling of the near-surface air over a sloping surface, which forces a 
downslope pressure gradient inducing a downslope gravitational flow (Parish and Bromwich, 1991), errors in the orography of the model are expected to result in errors in the wind field. Owing to the limited horizontal resolution of the model (approximately $55 \mathrm{~km}$ ) the surface slope in the escarpment region is seriously underestimated. Not only will a decrease in $z_{0 m}$ therefore improve the modelled wind speed, but a better representation of the surface slope will probably improve the modelled wind speed as well.

\subsubsection{Temperature}

The effect of changes in $z_{0 m}$ and $z_{0 h}$ on near-surface temperature is more complicated and is only to some extent directly related to changes in $z_{0 m}$ and $z_{0 h}$. Changes in near-surface stability and small changes in the large-scale circulation patterns owing to changes in the advection patterns of heat also affect the temperature. The circulation patterns differ slightly for each experiment as do the temperature patterns. The monthly averaged regional changes over the continent with respect to CTL may range between $\pm 3{ }^{\circ} \mathrm{C}$ in January and $\pm 10{ }^{\circ} \mathrm{C}$ in July (not shown). The largest changes in the monthly means are significant at the 5\% level and are related to changes in the circulation patterns. The magnitude of the temperature variations is very similar to those presented by King et al. (2001) who studied the effect of different formulations of the stability functions on the surface fluxes and near-surface conditions. The large variations in July are due to the fact that the horizontal and vertical temperature gradients in winter are larger than in summer. Averaged over the continent the surface temperature decreases and the temperature at the lowest model level increases (except in CNS) compared to CTL (Table III). This results in an increase in the temperature gradient between the surface and the lowest model level and an increase in near-surface static stability, which is largest for AND and ANDC.

The modelled monthly averaged 2-m air temperatures are compared with measurements in Figure 7 and Table IV. The 2-m temperature is reasonably well modelled in all experiments with average biases of less than $1{ }^{\circ} \mathrm{C}$. Differences are smaller than $4{ }^{\circ} \mathrm{C}$ for most of the sites in all experiments. In January the 2-m temperature is on average overestimated in all experiments with the largest overestimation $\left(6{ }^{\circ} \mathrm{C}\right)$ at sites on the Antarctic plateau. This overestimation is partly due to a too low constant albedo of 0.8 in the model resulting in a too large warming of the surface by the sun, which is largest for stations where the cloud cover is lowest. In July the 2-m temperature is on average underestimated by the model. The difference is largest at stations at the edge of the Ross ice shelf where the model underestimates the temperature by $>6^{\circ} \mathrm{C}$. This underestimation is partly explained by a too large surface temperature inversion owing to too low near-surface wind speeds. The bias and $\sigma$ is slightly smaller for experiments with only a reduced $z_{0 h}$ (CNS and AND). 

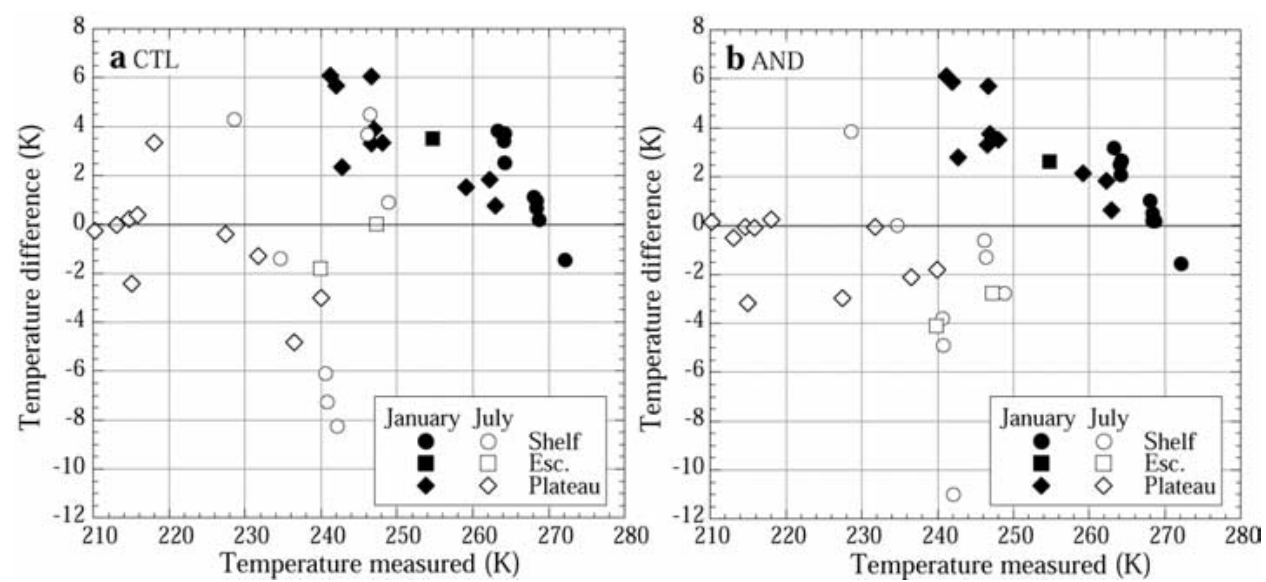

Figure 7. Monthly averaged 2-m temperature difference (model-measurements) as a function of measurements for CTL (a) and AND (b). Closed symbols represent January values, open symbols July values, Esc. is the escarpment.

\subsubsection{Turbulent Fluxes}

Changing $z_{0 m}$ and $z_{0 h}$ has a direct effect on the magnitude of the turbulent fluxes of heat $(H)$ and moisture $(L E)$, as well as an indirect effect through changing the near-surface wind speed, temperature and specific humidity gradients. Lowering $z_{0 m}$ and $z_{0 h}$ has the general effect of reducing the magnitude of the turbulent fluxes (Table III) owing to a decrease in $u_{*}$ and increase in static stability of the boundary layer. (Fluxes towards the surface are defined positive, $L$ above is the latent heat of vaporization.) Lowering $z_{0 h}$ has the largest effect in AND and ANDC. Note that monthly and continentally averaged $H+L E \approx 0$ in January and $H+L E>0$ in July. Over the Antarctic plateau changes in $H$ and $L E$ are small.

Over large parts of the continent $L E$ is positive in July $\left(0\right.$ to $\left.5 \mathrm{~W} \mathrm{~m}^{-2}\right)$ indicating that deposition occurs in all experiments; the amount of deposition decreases when decreasing $z_{0 m}$ and $z_{0 h}$. The reduction in both $H$ and $L E$ is largest in the escarpment regions and mountainous areas where the change in $z_{0 h}$ is largest (Figure 8). In these areas the change in the monthly mean fields of $H$ and $L E$ is significant at the 5\% level. Extreme values of $H$ found in the escarpment regions in CTL are $80 \mathrm{~W} \mathrm{~m}^{-2}$ in January and $100 \mathrm{~W} \mathrm{~m}^{-2}$ in July. Reducing $z_{0 h}$ typically reduces these values to $45 \mathrm{~W} \mathrm{~m}^{-2}$ in January and $80 \mathrm{~W} \mathrm{~m}^{-2}$ in July. $L E$ is negative in the escarpment region indicating sublimation. Reducing $z_{0 h}$ generally results in the diminishing of the areas with extreme amounts of sublimation as found by Van Lipzig et al. (2002). Extreme values of $L E$ found in the escarpment regions in CTL are $-45 \mathrm{~W} \mathrm{~m}^{-2}$ in January and $-40 \mathrm{~W} \mathrm{~m}^{-2}$ in July. Reducing $z_{0 h}$ typically reduces these values to $-30 \mathrm{~W} \mathrm{~m}^{-2}$ in January and $-10 \mathrm{~W} \mathrm{~m}^{-2}$ in July. The magnitude of the variations in $H$ is very similar to those presented by King et al. (2001) for their experiments where the stability functions are changed at the surface and in the boundary layer. An interesting feature in the fields of $H$ and $L E$, as well as the 
wind speed, is the dipole pattern in the Lambert Glacier basin (Figures 5 and 8), which is most pronounced in CNSC and ANDC.

The reduction of the turbulent fluxes due to a reduced $z_{0 h}$ improves the correspondence between model and measurements (Figure 9 and Table IV). The measured fluxes are indirect, and determined from measurements of wind speed, temperature and humidity using Monin-Obukhov similarity theory (Reijmer and Oerlemans, 2002). The improvement is largest at the sites where the reduction in $z_{0 h}$ with respect to CTL is largest, i.e., at the stations in the escarpment region (not shown). Figure 9 presents the difference between modelled and measured fluxes as a function of the measurements. Note that the uncertainty in the measured fluxes is considerable (50\%) and is brought about by the uncertainty in the measurements and method. Compared to the measurements $H$ is systematically 14 to $21 \mathrm{~W} \mathrm{~m}^{-2}$ overestimated in the model. $L E$ is systematically underestimated $(-1.5$ to $-5 \mathrm{~W} \mathrm{~m}^{-2}$ ), which results in too much sublimation, especially in January. Net radiation over Antarctica is negative and except near the coast almost completely balanced by a positive (towards the surface) $H$. The net radiative flux is systematically $12 \mathrm{~W} \mathrm{~m}^{-2}$ too large in winter (not shown). The systematic difference in the heat fluxes and with that in the radiative fluxes is probably due to the incapacity of atmospheric models to represent heat transfer under very stable conditions (King and Connolley, 1997). Overall, application of the surface renewal model of Andreas (1987) (AND and ANDC) gives for the turbulent fluxes the best correspondence with the measurements.

\subsection{THE VERTICAL PROFILES}

\subsubsection{Wind Speed}

The changes at the surface propagate to the overlying atmosphere, affecting the profiles of wind speed, temperature and humidity. In atmospheric models the main impact of the (stable) boundary layer on the rest of the atmosphere is through the surface fluxes by way of vertical diffusion (Beljaars and Viterbo, 1998). In a stable boundary layer the main impact is through the momentum flux. Therefore, the most pronounced changes are found in the wind speed profiles and are mainly produced by changes in $z_{0 m}$. Figure 10 presents the continentally and monthly averaged profiles of the zonal and meridional component of the wind speed. The profiles show the expected increase in wind speed in the boundary layer. The variations caused by changes in $z_{0 h}$ (CNS and AND) are an order of magnitude smaller than the changes due to changing $z_{0 m}$ (CNSC and ANDC). The wind speed profiles also exhibit large variations above the boundary layer where the magnitude of the wind increases, with the largest increase in experiments CNSC and ANDC (not shown). The changes in wind speed are most pronounced in the zonal component of the wind speed in January. The layer where south-easterly near-surface winds prevail thickens considerably and the strength of the westerly large-scale flow decreases. In July this change is an order of magnitude smaller and not visible in Figure 10. 

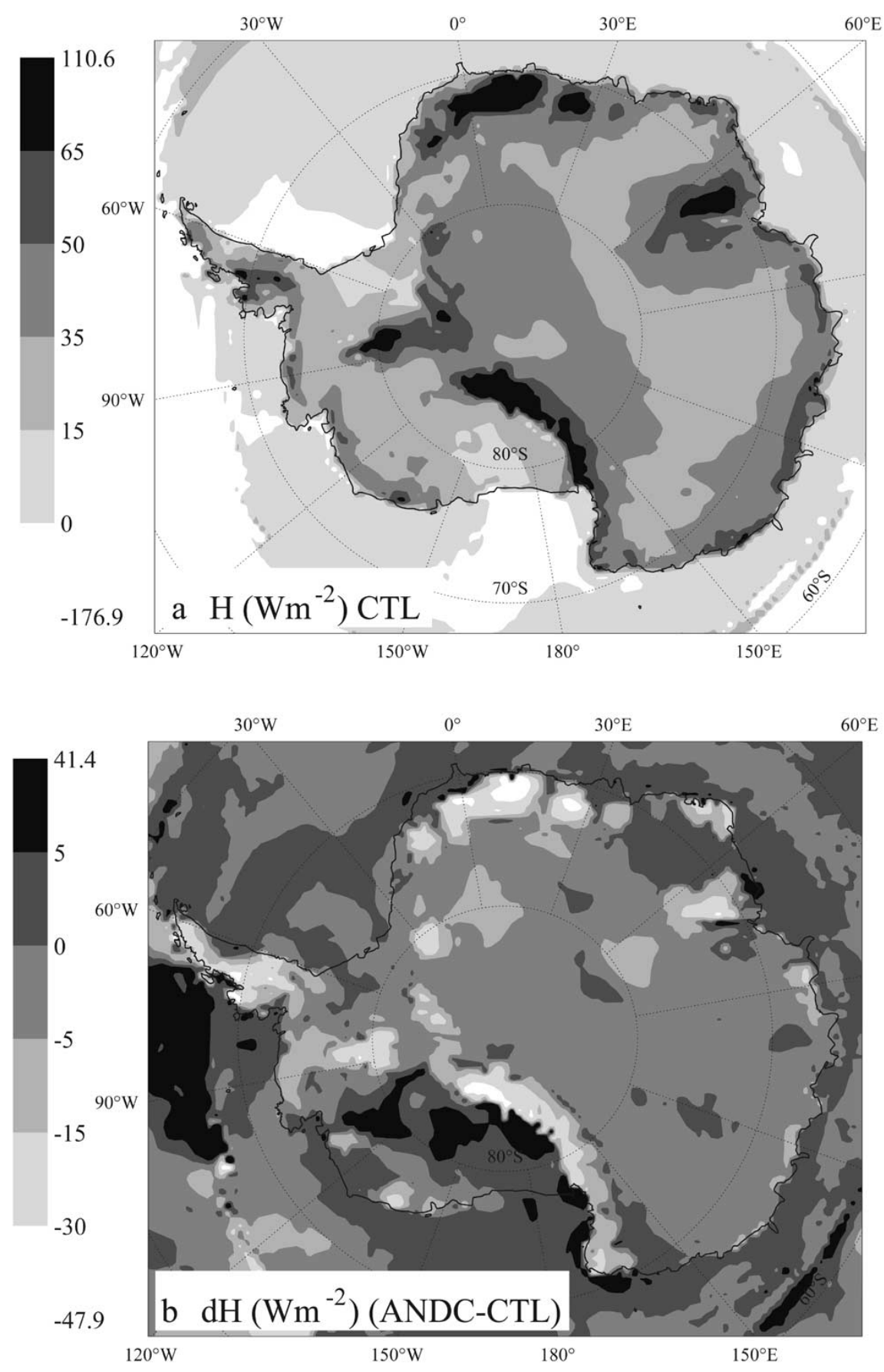

Figure 8. Monthly averaged surface sensible heat flux $(H)$ for CTL (a), sensible heat flux difference (dH, ANDC-CTL) (b), surface latent heat flux ( $L E)$ for CTL (c) and latent heat flux difference (dLE, ANDC-CTL) (d) for July 1998. Fluxes towards the surface are defined positive. 

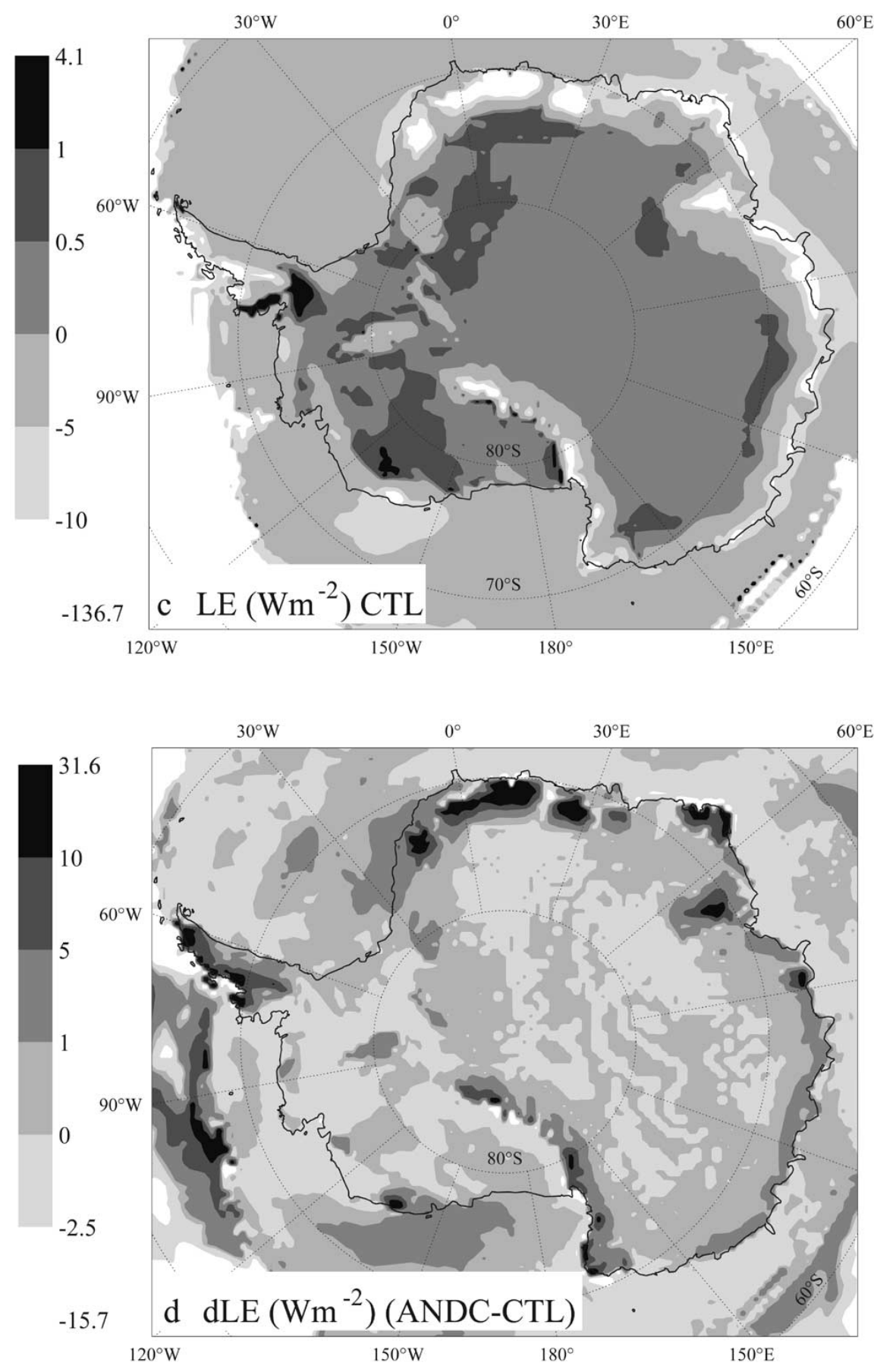

Figure 8. Continued. 

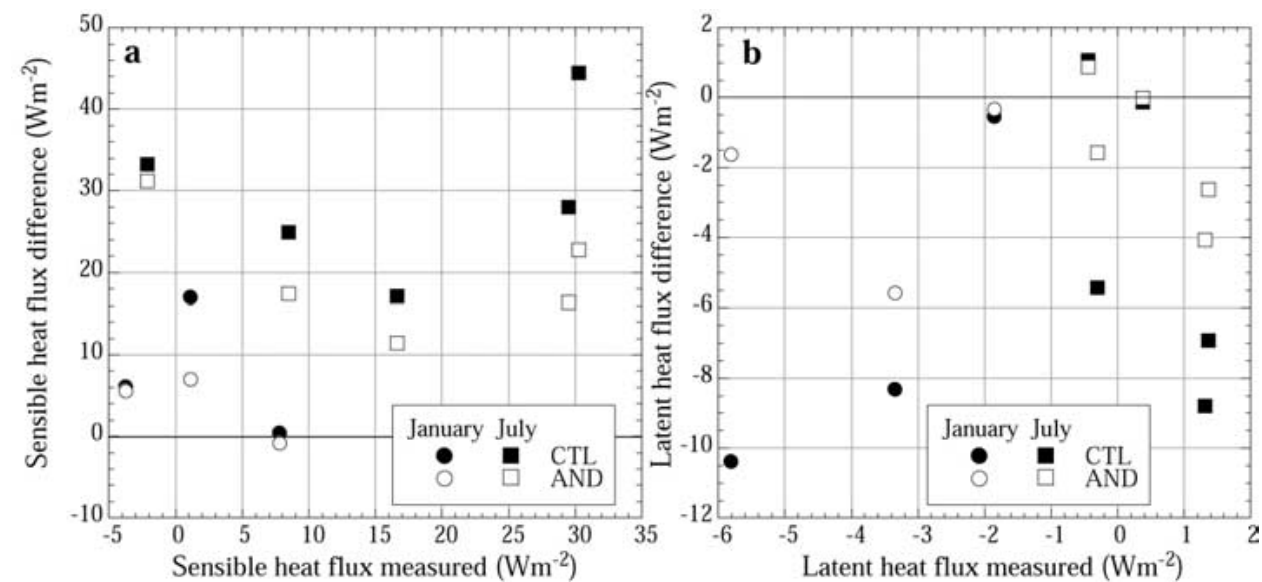

Figure 9. Monthly averaged difference (modelled-measurements) of the surface sensible (a) and latent (b) heat flux as a function of measurements for experiments CTL and AND. Fluxes towards the surface are defined positive. The measurements are fluxes determined from measurements of wind speed, temperature and humidity using Monin-Obukhov similarity theory. Note that only data from the DML AWS are available.

This difference between the January and July responses to a change in surface roughness is related to the vertical diffusion in the model. The vertical diffusion depends on the Richardson number and increases for decreasing stability. Since the atmosphere in summer is less stable than in winter the effect of a change in roughness length on the momentum budget is largest in summer.

Comparison of modelled profiles with measurements is difficult since most sites with regular balloon soundings are topographically complicated sites. South Pole is located at the edge of the Antarctic plateau close to the Transantarctic mountain range, and Neumayer is located on an ice shelf reasonably close to the coast. The specific local topographic details especially affect the wind speed and direction profiles. Figure 11 presents the monthly averaged modelled and measured wind speed profiles at Neumayer and South Pole in January and July 1998. The wind speed profiles from the different experiments are very similar for both stations and compare reasonably well with the measurements, although differences of 2 to $4 \mathrm{~m} \mathrm{~s}^{-1}$ between the experiments do occur. Differences between the experiments occur in the strength of the near-surface maximum and, at Neumayer, also in the strength and altitude of the higher altitude minimum. Except at South Pole in July, a decrease in $z_{0 m}$ and/or $z_{0 h}$ reduces the near-surface wind speed maximum at these two locations. In January at Neumayer, wind speeds are generally too low while in July they are generally too high. At South Pole, wind speeds are generally too low near the surface and too high at higher altitudes. The model reproduces the layer with constant wind speeds above the surface layer at South Pole reasonably well. However, none of the experiments significantly improves the model results at these sites. 

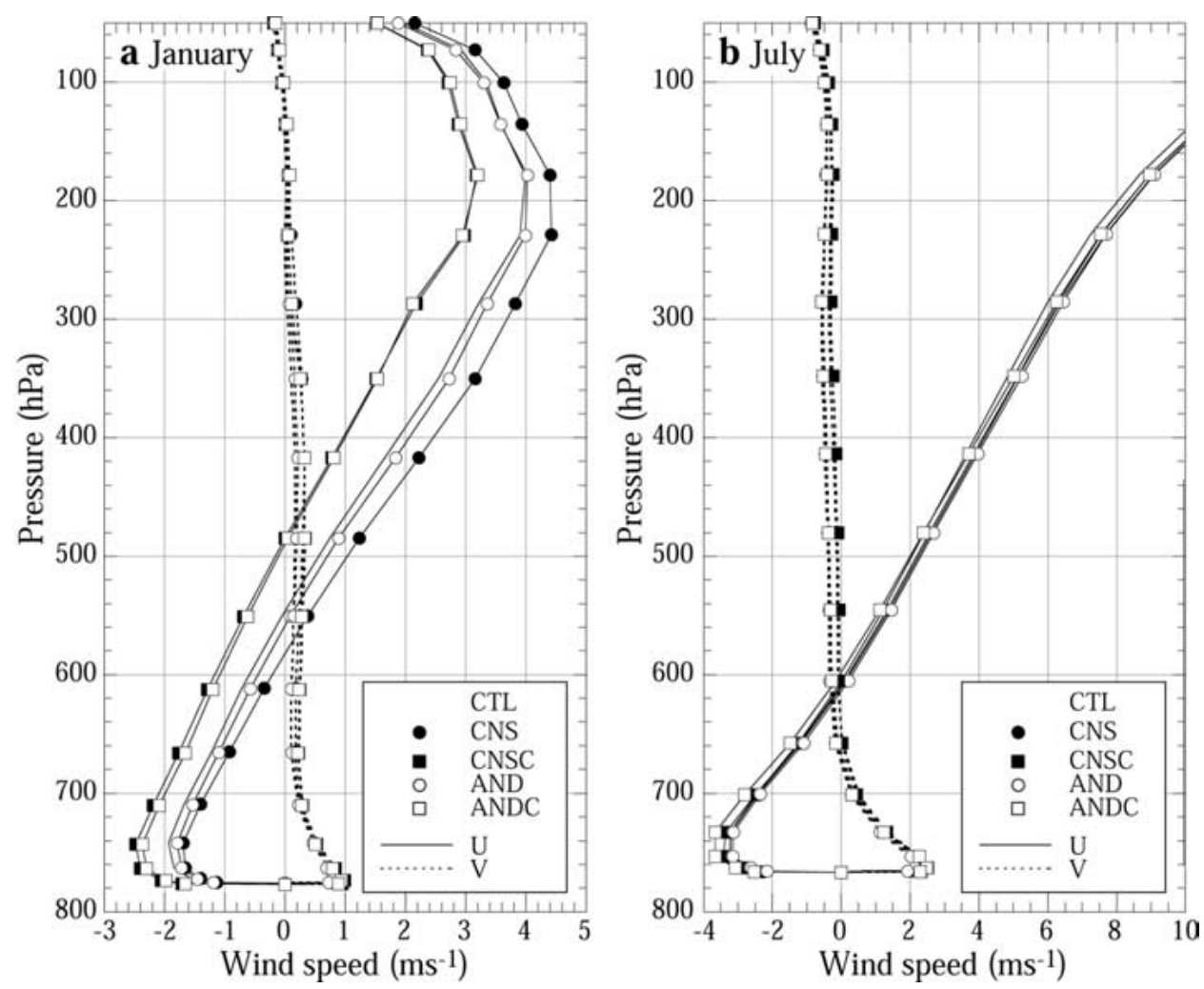

Figure 10. Monthly and continentally averaged profiles of the zonal (straight lines, $U$ ) and meridional (dotted lines, $V$ ) component of the wind speed for January (a) and July (b) 1998.

\subsubsection{Temperature}

Averaged over the continent and over a month the variations in the temperature profiles owing to changes in the roughness lengths are confined to the lower troposphere and are on the order of $0.6{ }^{\circ} \mathrm{C}$ (not shown). Between the different experiments there is not much difference in magnitude or lapse rate of the profiles, which is due to the stable stratification of the boundary layer suppressing the effect of changes at the surface on the temperature profile. However, as seen in Table III, the static stability of the boundary layer slightly increases with a decrease in $z_{0 m}$ and/or $z_{0 h}$.

At individual sites the variations between the experiments are larger, between 0.5 and $2.0^{\circ} \mathrm{C}$. Figure 12 presents the monthly averaged potential temperature profiles as measured and modelled at Neumayer and South Pole in January and July 1998. The figure shows that the lapse rates of the modelled profiles are very similar for each site and month. At Neumayer the modelled lapse rates are in reasonable agreement with the measurements. In January model temperatures are 1 to $3{ }^{\circ} \mathrm{C}$ too high while in July they are 1 to $3{ }^{\circ} \mathrm{C}$ too low, in agreement with the difference between modelled and measured 2-m temperatures. The measurements 

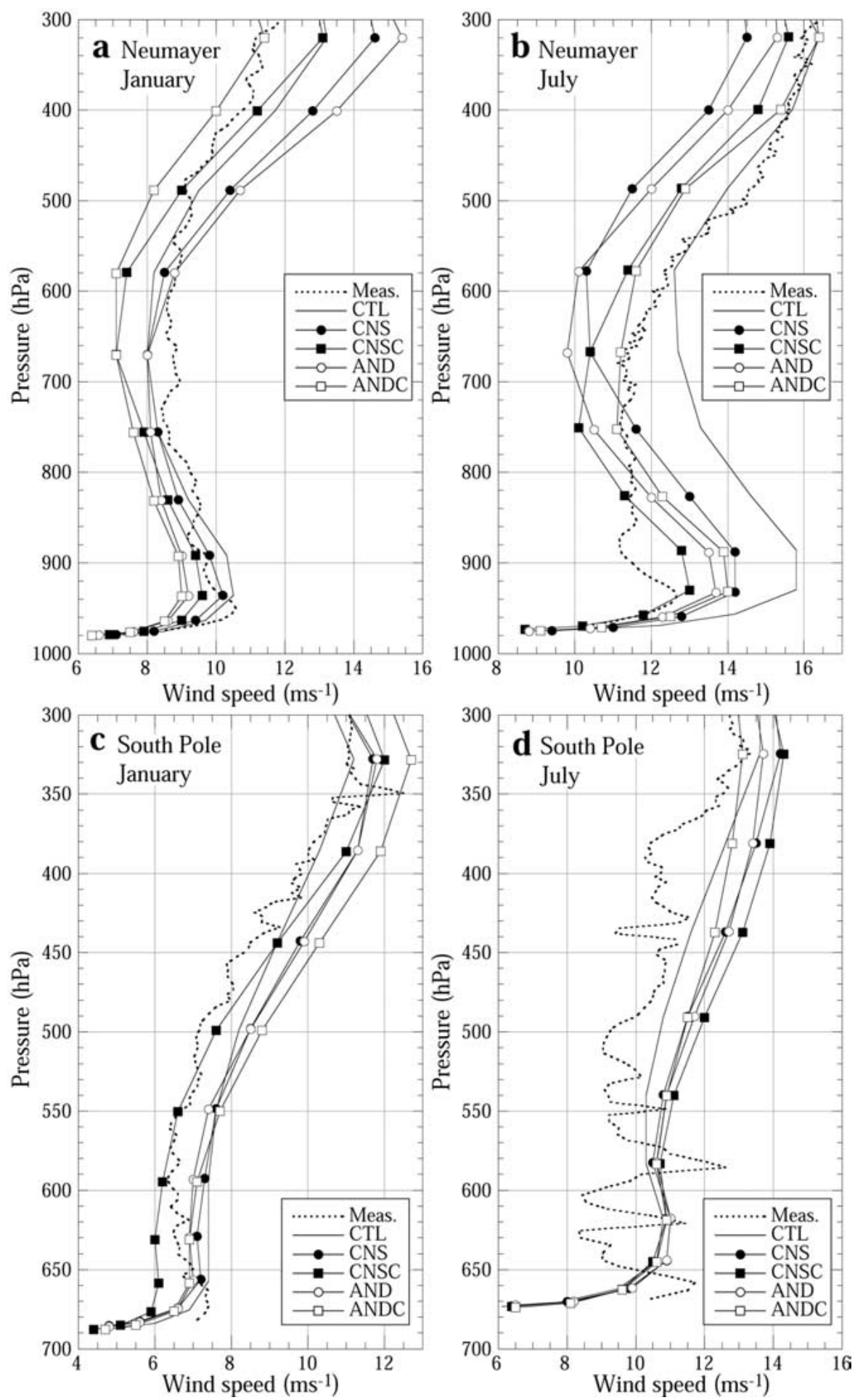

Figure 11. Monthly averaged profiles of wind speed at Neumayer (a, b) and South Pole (c, d) for January (a, c) and July (b, c) 1998. 
at Neumayer are best represented by experiment CNSC and ANDC in January and by ANDC in July. At South Pole the correspondence between model and measurements is not as good. In January, the modelled potential temperature profile shows more stable conditions throughout the atmosphere. The model captures the strong inversion in July although the measurements show larger stability in the boundary layer. A decrease in $z_{0 m}$ and/or $z_{0 h}$ does not improve the results significantly.

\section{Summary and Concluding Remarks}

We use the Regional Atmospheric Climate Model RACMO to examine the effects of changes in the roughness lengths for momentum and heat on the structure of the lower atmosphere and the surface energy fluxes. We performed four experiments in which we altered $z_{0 m}$ and/or $z_{0 h}$ with respect to a control experiment. The changes consisted of a lowering of $z_{0 m}$ from a control field, with an orographic correction based on the ECMWF $z_{0 m}$ field, to a constant value of $10^{-3} \mathrm{~m}$, and a lowering of $z_{0 h}$ from equal to $z_{0 m}$ to a constant value of $10^{-3} \mathrm{~m}$, or a value dependent on the wind speed via the surface renewal model of Andreas (1987).

The reduction of $z_{0 m}$ results in the expected increase in near-surface wind speed, which is largest in the escarpment regions where the changes in $z_{0 m}$ are largest. These are also the areas where the change in the monthly mean fields is significant at the 5\% level. Changes in $z_{0 h}$ have little effect on the magnitude of the wind speed owing to the stability of the boundary layer. The effect of a reduced $z_{0 m}$ is not confined to the boundary layer. Wind speed increase over the whole troposphere due to a reduction in $z_{0 m}$ and/or $z_{0 h}$. On average the depth of the layer where south-easterly near-surface winds prevail increases and the influence of the westerly large-scale flow reduces. This effect is most pronounced in summer and is explained by the fact that in atmospheric models vertical diffusion is mainly responsible for the vertical transport of momentum. The vertical diffusion is a function of the Richardson number and increases with decreasing stability, explaining the larger impact of changing $z_{0 m}$ in summer.

Comparison to measurements shows that for the wind speed the reduction of $z_{0 \mathrm{~m}}$ to $10^{-3} \mathrm{~m}$ is generally too severe. A correction for the influence of subgrid-scale orography on the grid-averaged flow remains necessary. This correction must be resolution dependent since a better representation of the orography, especially the surface slope, will improve the modelled near-surface wind field. The individual wind speed profiles are reasonably well reproduced by the model compared to measurements. The differences are partly explained by the topographically complicated locations of the measurement sites and by small differences between the modelled and actual occurred large-scale flow patterns.

Changes in the surface temperature and temperature profiles due to changes in the roughness lengths are equivocal. The general trend with a decreasing surface roughness is a decrease in surface temperature and an increase in atmospheric tem- 

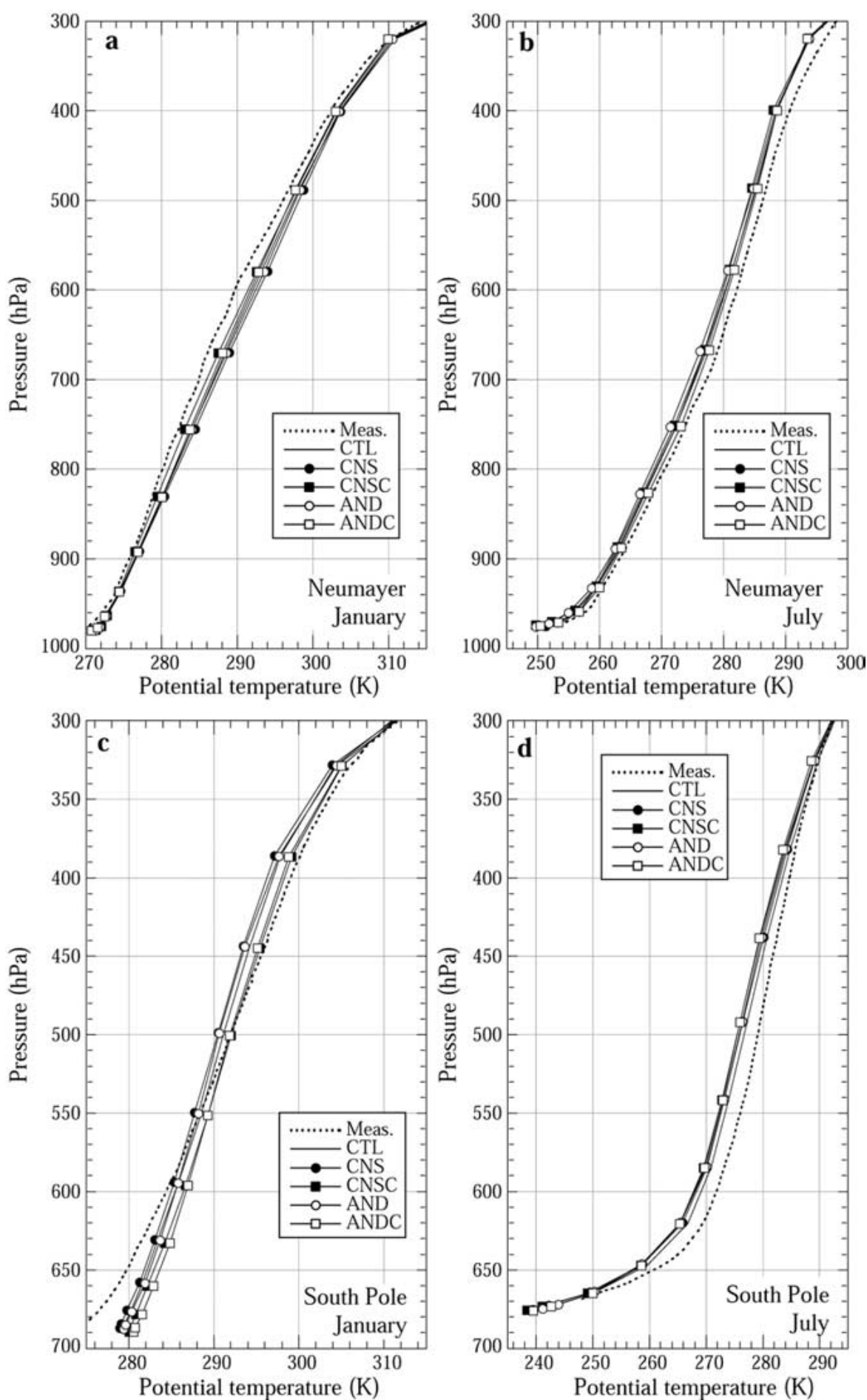

Figure 12. Monthly averaged profiles of potential temperature at Neumayer (a, b) and South Pole (c, d) for January (a, c) and July (b, c) 1998. 
perature resulting in an increase in static stability of the boundary layer. Changes in temperature are not only produced by changes in roughness lengths but also by small changes in flow patterns changing the advection of heat and moisture, plus changes in radiation caused by differing cloud cover. Compared to measurements the temperature is generally reasonably well represented. Largest deviations occur on the Antarctic plateau in summer and at the edges of the large ice shelves in winter. The overestimation of the surface temperature in summer is probably caused by a too low surface albedo in the model while the too low temperatures in winter are probably caused by a too stable stratification near the surface and insufficient exchange due to too low wind speeds.

The surface heat fluxes are on average reduced by the reductions in roughness length with the largest impact due to changes in $z_{0 h}$. In the areas where the reduction of $z_{0 m}$ and/or $z_{0 h}$ is largest the changes are significant at the $5 \%$ level. The agreement with the measurements improves considerably when reducing $z_{0 h}$, with the best results occurring when using the surface renewal method of Andreas (1987). It is site dependent, whether or not a reduction of $z_{0 m}$ improves the results even further. The effect of changing $z_{0 m}$ and/or $z_{0 h}$ on surface fluxes and surface temperature is very similar to changing the stability functions in the surface and boundary-layer schemes of an atmospheric model (King et al., 2001). This is to be expected since the roughness length and the stability functions are closely linked to the exchange coefficients that describe the vertical transfer of heat and moisture in atmospheric models. In general, we conclude that a reduction of $z_{0 h}$ is necessary to improve model results. Using Andreas (1987) is a good option but it must be noted that the scheme was developed for sea ice, although Andreas (2002) shows that it also performs reasonably well for Antarctic snow surfaces.

\section{Acknowledgements}

We thank the two reviewers for their useful comments on an earlier versions of the manuscript. Financial support was provided by the Netherlands Antarctic Research Programme (ALW), which is part of the Netherlands Organization of Scientific Research (NWO).

\section{References}

Andreas, E. L.: 1987, 'A Theory for the Scalar Roughness and the Scalar Transfer Coefficients over Snow and Sea Ice', Boundary-Layer Meteorol. 38, 159-184.

Andreas, E. L.: 2002, 'Parameterizing Scalar Transfer over Snow and Ice: A Review', J. Hydrometeorol. 3, 417-432.

Beljaars, A. C. M. and Viterbo, P.: 1994, 'The Sensitivity of Winter Evaporation to the Formulation of Aerodynamic Resistance in the ECMWF Model', Boundary-Layer Meteorol. 71, 135-149. 
Beljaars, A. C. M. and Viterbo, P.: 1998, 'Clear and Cloudy Boundary Layers', Role of the Boundary Layer in a Numerical Weather Prediction Model, Royal Netherlands Academy of Arts and Sciences, pp. 287-304.

Bintanja, R.: 2000, 'Surface Heat Budget of Antarctic Snow and Blue Ice: Interpretation of Spatial and Temporal Variability', J. Geophys. Res. 105, 24,387-24,407.

Bintanja, R. and Reijmer, C. H.: 2001, 'A Simple Parameterization for Snowdrift Sublimation over Antarctic Snow Surfaces', J. Geophys. Res. 106, 31,739-31,748.

Bintanja, R. and van den Broeke, M. R.: 1995, 'Momentum and Scalar Transfer Coefficients over Aerodynamically Smooth Antarctic Surfaces', J. Appl. Meteorol. 34, 902-926.

Cassano, J. J., Parish, T. R., and King, J. C.: 2001, 'Evaluation of Turbulent Surface Flux Parameterizations for the Stable Surface Layer over Halley, Antarctica', Mon. Wea. Rev. 129, 26-46.

Charnock, M.: 1955, 'Wind Stress on a Water Surface', Quart. J. Roy. Meteorol. Soc. 81, 639-640.

Christensen, J. H., Christenssen, O. B., Lopez, P., van Meijgaard, E., and Botzet, M.: 1996, The HIRHAM4 Regional Climate Model, Scientific Report 96-4, Danish Meteorological Institute, Copenhagen, Denmark, 51 pp.

Garratt, J. R.: 1992, The Atmospheric Boundary Layer, Cambridge University Press, Cambridge, $316 \mathrm{pp}$.

Gustafsson, N.: 1993, HIRLAM 2 Final Report, Technical Report No. 9, SMHI, Norrköping, Sweden.

Handorf, D., Foken, T., and Kottmeier, C.: 1999, 'The Stable Atmospheric Boundary Layer over an Antarctic Ice Sheet', Boundary-Layer Meteorol. 91, 165-189.

Inoue, J.: 1989, 'Surface Drag over the Snow Surface of the Antarctic Plateau: 2. Seasonal Change of the Surface Drag in the Katabatic Wind Region', J. Geophys. Res. 94, 2219-2224.

King, J. C.: 1990, 'Some Measurements of Turbulence over an Antarctic Ice Shelf', Quart. J. Roy. Meteorol. Soc. 116, 379-400.

King, J. C. and Anderson, P. S.: 1994, 'Heat and Water Vapour Fluxes and Scalar Roughness Lengths over an Antarctic Ice Shelf', Boundary-Layer Meteorol. 69, 101-121.

King, J. C. and Connolley, W. M.: 1997, 'Validation of the Surface Energy Balance over the Antarctic Ice Sheets in the U.K. Meteorological Office Unified Climate Model', J. Climate 10, 1273-1287.

King, J. C. and Turner, J.: 1997, Antarctic Meteorology and Climatology, Cambridge University Press, New York, 409 pp.

King, J. C., Connelley, W., and Derbyshire, S.: 2001, 'Sensitivity of Modelled Antarctic Climate to Surface and Boundary Layer Flux Parameterisations', Quart. J. Roy. Meteorol. Soc. 127, 779794.

König-Langlo, G. C., King, J. C., and Pettre, P: 1998, 'Climatology of the Three Coastal Antarctic Stations Dumont d'Urville, Neumayer, and Halley', J. Geophys. Res. 103, 10,935-10,946.

Krinner, G., Genthon, C., Li, Z.-X., and Van, P.: 1997, 'Studies of the Antarctic Climate with a Stretched-Grid General Circulation Model', J. Geophys. Res. 102, 13,731-13,745.

Louis, J. F.: 1979, 'A Parametric Model of Vertical Eddy Fluxes in the Atmosphere', Boundary-Layer Meteorol. 17, 187-202.

Parish, T. R. and Bromwich, D. H.: 1991, 'Continental-Scale Simulation of the Antarctic Katabatic Wind Regime', J. Climate 4, 135-146.

Reijmer, C. H. and Oerlemans, J.: 2002, 'Temporal and Spatial Variability of the Surface Energy Balance in Dronning Maud Land, Antarctica', J. Geophys. Res. 107, 4759-4770.

Roeckner, E., Arpe, K., Bengtsson, L., Christoph, M., Claussen, M., Dumeril, L., Esch, M., Giorgetta, M., Schlese, U., and Schulzweida, U.: 1996, The Atmospheric General Circulation Model ECHAM-4: Model Description and Simulation of Present-Day Climate, Report No. 218, Max-Planck-Institut für Meteorology, $96 \mathrm{pp}$.

Smeets, P.: 2000, Stable Boundary Layer over a Melting Glacier, Ph.D. Thesis, Vrije Universiteit, Amsterdam, The Netherlands, $117 \mathrm{pp}$. 
Stearns, C. R., Holmes, R. E., and Weidner, G. A.: 1997, 'Antarctic Automatic Weather Stations: 1996-1997', Antarct. J. U.S. 32, 174-178.

Turner, J., Connelley, W. M., Leonard, S., Marshall, G. J., and Vaughan, D. G.: 1999, 'Spatial and Temporal Variability of Net Snow Accumulation over the Antarctic from ECMWF Re-Analysis Project Data', Int. J. Climatol. 19, 697-724.

Van den Broeke, M. R., van Lipzig, N. P. M., and van Meijgaard, E.: 2002, 'Momentum Budget of the East-Antarctic Atmospheric Boundary Layer: Results of a Regional Climate Model', J. Atmos. Sci. 59, 3117-3129.

Van Lipzig, N. P. M., van Meijgaard, E., and Oerlemans, J.: 1999, 'Evaluation of a Regional Atmospheric Model Using Measurements of Surface Heat Exchange Processes from a Site in Antarctica', Mon. Wea. Rev. 127, 11,994-12,011.

Van Lipzig, N. P. M., van Meijgaard, E., and Oerlemans, J.: 2002, 'The Spatial and Temporal Variability of the Surface Mass Balance in Antarctica: Results from a Regional Climate Model', Int. J. Climatol. 22, 1197-1217.

Zilitinkevich, S. S., Perov, V. L., and King, J. C.: 2002, 'Near-Surface Turbulent Fluxes in Stable Stratification: Calculation Techniques for Use in General-Circulation Models', Quart. J. Roy. Meteorol. Soc. 128, 1571-1587. 
